\title{
Effects of Nanosilica on Early Age Stages of Cement Hydration
}

\author{
Forood Torabian Isfahani, ${ }^{1}$ Elena Redaelli, ${ }^{1}$ Weiwen $\mathrm{Li}^{2}{ }^{2}$ and Yaru Sun ${ }^{2}$ \\ ${ }^{1}$ Politecnico di Milano, Department of Chemistry, Materials and Chemical Engineering "G. Natta", \\ Via Mancinelli 7, 20131 Milan, Italy \\ ${ }^{2}$ College of Civil Engineering, Shenzhen University, Nanshan, Shenzhen 518060, China \\ Correspondence should be addressed to Forood Torabian Isfahani; forood.torabian@polimi.it
}

Received 26 July 2017; Revised 20 August 2017; Accepted 28 August 2017; Published 12 October 2017

Academic Editor: Jim Low

Copyright (C) 2017 Forood Torabian Isfahani et al. This is an open access article distributed under the Creative Commons Attribution License, which permits unrestricted use, distribution, and reproduction in any medium, provided the original work is properly cited.

\begin{abstract}
Effects of nanosilica on cement hydration have been broadly investigated in the literature and early age cement hydration, as a whole, has been mainly considered, disregarding the substages of the hydration. The hydration of cement is characterized by different substages and nanosilica effect on the hydration could be a result of diverse, even contradictory, behavior of nanosilica in individual stages of the hydration. In this study, effects of nanosilica on different substages of cement hydration are investigated. Isothermal calorimetry results show that at early ages (initial 72 hours) the effects of nanosilica depend on the phenomenon by which the hydration is governed: when the hydration is chemically controlled, that is, during initial reaction, dormant period, and acceleratory period, the hydration rate is accelerated by adding nanosilica; when the hydration is governed by diffusion process, that is, during postacceleratory period, the hydration rate is decelerated by adding nanosilica. The Thermal Gravimetric Analysis on the samples at the hardened state (after 28 days of curing) reveals that, after adding nanosilica, the hydration degree slightly increased compared to the plain paste.
\end{abstract}

Dedicated to memory of professor Luca Bertolini for his contribution to this work

\section{Introduction}

Nanosilica (NS) has attracted considerable attention in recent years for developing new cementitious materials. Incorporation of NS has been proposed as a means to improve the strength [1-3] and the durability properties of cement composites [4-6]. It is broadly known that NS accelerates the early cement hydration rate. The mechanism of acceleration has been claimed to be through increasing dissolution of cement particles in the early stage [7-10]. NS has very high specific surface area compared to the cement grains, and thus it favors superficial dissolution of the cement particles. NS could also accelerate the early cement hydration rate through acting as seeds for precipitation of very first calcium silicate hydrates (C-S-H) [11]; however seeding effect of NS has been doubted by some researchers [12].

Figure 1 shows a typical heat flow per cement mass of a cement paste, measured by isothermal calorimetry. This figure shows various substages of hydration in the initial 30 hours after the cement comes into contact with mixing water. According to [13], the hydration of Portland cement pastes at ambient temperature is characterized by several stages.

Initial Reaction (before Induction). Upon contact of cement grains with water, rapid surface dissolution of ionic species and formation of hydrated products get under way. Tricalcium aluminate $\left(\mathrm{C}_{3} \mathrm{~A}\right)$ and tricalcium silicate $\left(\mathrm{C}_{3} \mathrm{~S}\right)$ dissolve and react, with a much higher rate for $\mathrm{C}_{3} \mathrm{~A}$ compared to $\mathrm{C}_{3} \mathrm{~S}$ [14-16]. This period appears to last for approximately an hour and then to be slowed down by precipitation of a layer of hydrates on the surface of cement grains.

Induction Period (Dormant). In this stage hydration of all clinker minerals progresses very slowly for approximately up to 3 hours. 


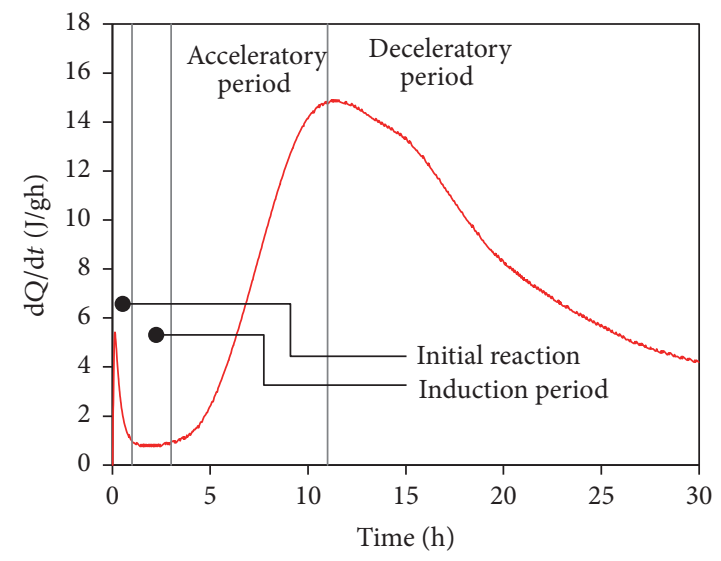

Figure 1: A typical heat flow curve versus time, measured by isothermal calorimetry. Different stages of hydration are shown in the figure.

Acceleratory Stage. In this period the progress of hydration is accelerated again by $\mathrm{C}_{3} \mathrm{~S}$ hydration for 3-11 hours after mixing.

Some researchers $[13,17]$ stated that the rate of reaction in initial reaction, induction, and acceleratory periods is controlled by nucleation and growth of the C-S-H formed in the main reaction. In other words, these periods are chemically controlled [18].

Deceleratory Period (after Acceleration). In this period the hydration rate slows down gradually, as the amount of still nonreacted material declines. The hydration rate changes from chemical control to diffusional control [18]. This period is followed by a slow continued reaction.

Since the cement hydration at early ages is governed by two phenomena, NS might have different influence on each individual stage of the hydration. In the existing literature, effects of NS on the cement hydration rate at early ages (e.g., initial 72 hours), as a whole, were repeatedly investigated, while those effects could be a result of diverse, even contradictory, behavior of NS in each substage of the early age hydration shown in Figure 1. Effects of NS on the cement hydration considering different substages, governed by chemical or diffusional process, have not received much attention in the literature. Thus, there is a need to clarify how NS can influence cement hydration at each individual stage.

In addition, effects of NS on the early age of cement hydration alone might not be fully representative of NS capability to boost cement properties, since they might appear later. Hou et al. [10] believe that NS accelerates cement hydration rate at early ages but hinders it at later ages. Consequently, for investigating effects of NS on the cement hydration in different stages of hydration, not only should its effects on the early ages be considered, but also its effects on the hydration at hardened state need to be studied.

In this study, the early age cement hydration was evaluated through isothermal calorimetry analysis on NS-blended pastes and compared with plain pastes without NS. Thermal Gravimetric Analysis (TGA) was performed as a means of evaluating cement hydration degree. Compressive strength test was also performed on hardened cement pastes after 28
TABLE 1: Composition of cement pastes.

\begin{tabular}{ccccc}
\hline \multirow{2}{*}{ w/c } & \multirow{2}{*}{ NS content (\%) } & \multicolumn{3}{c}{ Composition kg/m $\mathrm{m}^{3}$} \\
& & Cement & Water & NS \\
\hline 0.5 & 0 & 1187 & 593 & 0 \\
0.5 & 1.5 & 1169 & 593 & 18 \\
0.5 & 2.5 & 1157 & 593 & 30 \\
\hline
\end{tabular}

days of curing. Further information about microstructural changes was provided by Scanning Electron Microscope (SEM) and Mercury Intrusion Porosimetry (MIP).

\section{Materials and Experimental Methods}

Cement pastes were prepared with ordinary Portland cement CEM I 42.5R. Colloidal NS was added with concentration of $10 \%$ by weight of water and nominal particle size of $20 \mathrm{~nm}$. SEM image of dried NS can be seen in Figure 2, showing particle size of NS agglomerates lower than $100 \mathrm{~nm}$. Particle size distribution of the NS suspension, by Dynamic Light Scattering (DLS), is shown in Figure 3, showing that $76 \%$ of the suspension volume had particle size lower than $20 \mathrm{~nm}$.

The NS suspension was added to the mixing water taking into account its water content. Table 1 summarizes the composition of the cement pastes samples. Cement pastes with water-to-cement (w/c) ratio of 0.5 and NS dosages of $0 \%$, $1.5 \%$, and $2.5 \%$ with respect to cement mass were examined and NS was added as replacement of cement.

Isothermal Calorimetry. The total mass of binder (i.e., cement and NS) for each paste was $5 \mathrm{~g}$. The heat flow and cumulative heat of hydration after mixing cement with water were recorded for 72 hours by isothermal calorimetry instrument (Tony Technik 7338). Two samples were examined for each mix of Table 1. For cumulative released heat, an average of two values with its variation was reported.

Thermal Analysis. Fragments of hardened cement pastes were collected from broken samples of the compressive strength test after 28 days of wet curing. The fragments were ground. 


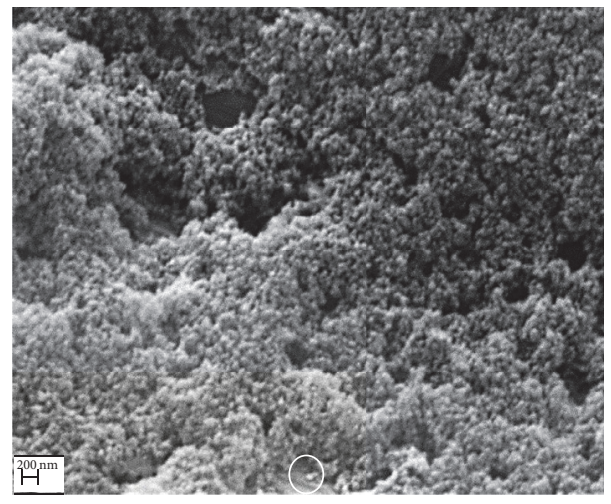

FIGURE 2: SEM micrograph of nanosilica suspension after drying. The white circle shows typical agglomerates of NS with a size smaller than $100 \mathrm{~nm}$.

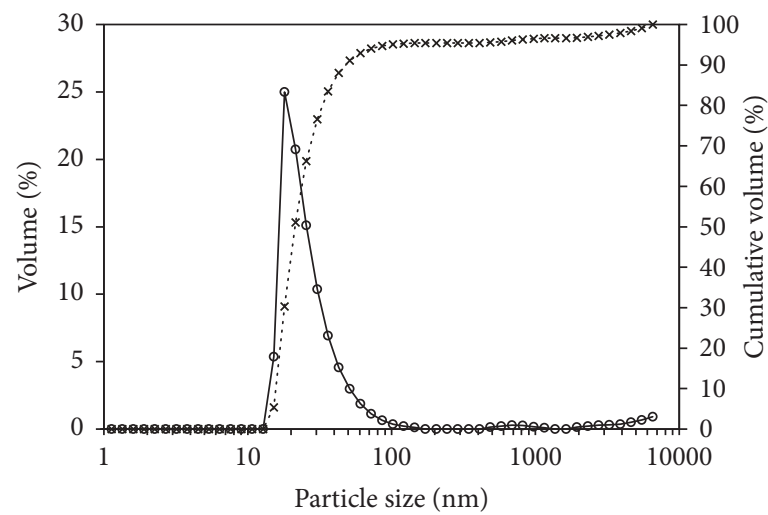

FIGURE 3: Particle size distribution of NS suspension by Dynamic Light Scattering method.

An isothermal analyzer (Netzsch model STA 409 PC) was used to perform the Thermal Gravimetric Analysis (TGA) and Differential Thermal Analysis (DTA) at the rate of $10^{\circ} \mathrm{C} / \mathrm{min}$ under a nitrogen flow of $50 \mathrm{ml} / \mathrm{min}$. The temperature was increased from $25^{\circ} \mathrm{C}$ to $105^{\circ} \mathrm{C}$ and remained at $105^{\circ} \mathrm{C}$ for 2 hours to promote removal of free water; then it was increased to $900^{\circ} \mathrm{C}$.

According to Pane and Hansen [19], the weight losses in the temperature range of $440-520^{\circ} \mathrm{C}$ and $660-770^{\circ} \mathrm{C}$ are associated with decomposition of calcium hydroxide $(\mathrm{CH})$ and calcium carbonate (CC), respectively. The $\mathrm{CH}$ and $\mathrm{CC}$ contents can be calculated with the following formulas:

$$
\begin{aligned}
& \mathrm{CH}(\%)=\mathrm{WL}_{\mathrm{CH}}(\%) \times \frac{\mathrm{MW}_{\mathrm{CH}}}{\mathrm{MW}_{\mathrm{H}}}, \\
& \mathrm{CC}(\%)=\mathrm{WL}_{\mathrm{CC}}(\%) \times \frac{\mathrm{MW}_{\mathrm{CC}}}{\mathrm{MW}_{\mathrm{CO}_{2}}},
\end{aligned}
$$

where $\mathrm{WL}_{\mathrm{CH}}$ and $\mathrm{WL}_{\mathrm{CC}}$ represent the weight losses associated with $\mathrm{CH}$ and $\mathrm{CC}$ decomposition, respectively. $\mathrm{MW}_{\mathrm{CH}}$, $\mathrm{MW}_{\mathrm{H}}, \mathrm{MW}_{\mathrm{CC}}$, and $\mathrm{MW}_{\mathrm{CO}_{2}}$ represent molecular weights of $\mathrm{CH}(74.01 \mathrm{~g} / \mathrm{mol})$, water $(18 \mathrm{~g} / \mathrm{mol}), \mathrm{CC}(100 \mathrm{~g} / \mathrm{mol})$, and carbon dioxide $(44 \mathrm{~g} / \mathrm{mol})$, respectively.

The hydration degree can be obtained from the thermal analysis results. In this study, loss-on-ignition measurements of nonevaporable water content of the hydrated cement pastes were used [20]. The mass of nonevaporable water, $M_{\text {water }}$, between 105 and $900^{\circ} \mathrm{C}$ was determined according to the following equation:

$$
M_{\text {water }}(g)=M_{105}(g)-M_{900}(g)-M_{\mathrm{CaCO}_{3}}(g),
$$

where $M_{105}, M_{900}$, and $M_{\mathrm{CaCO}_{3}}$ represent the mass of the paste substance after heat treatment at $105^{\circ} \mathrm{C}$, after heat treatment at $900^{\circ} \mathrm{C}$, and caused by the decomposition of CC, coming from still unreacted cement, during heating. Then, the hydration degree (\%) of the cement at time $t, \beta_{t}$, was calculated as

$$
\beta_{t}=\frac{M_{\text {water }}}{M_{\text {water-full }}}
$$

where $M_{\text {water-full }}$ is the water required for the full hydration of cement. The value of $M_{\text {water-full }}$ employed in this study is $0.23 \mathrm{~g}$ for $1 \mathrm{~g}$ cement based on the results reported by Pane and Hansen [19].

Compressive Strength. Three $40 \times 40 \times 160 \mathrm{~mm}$ prismatic samples were cast for each batch. The samples were demoulded the day after casting and then cured in a curing chamber with $95 \%$ relative humidity and $23^{\circ} \mathrm{C}$ temperature for 28 days. The test was performed according to standard EN 196-1 and the average of six values was reported. 


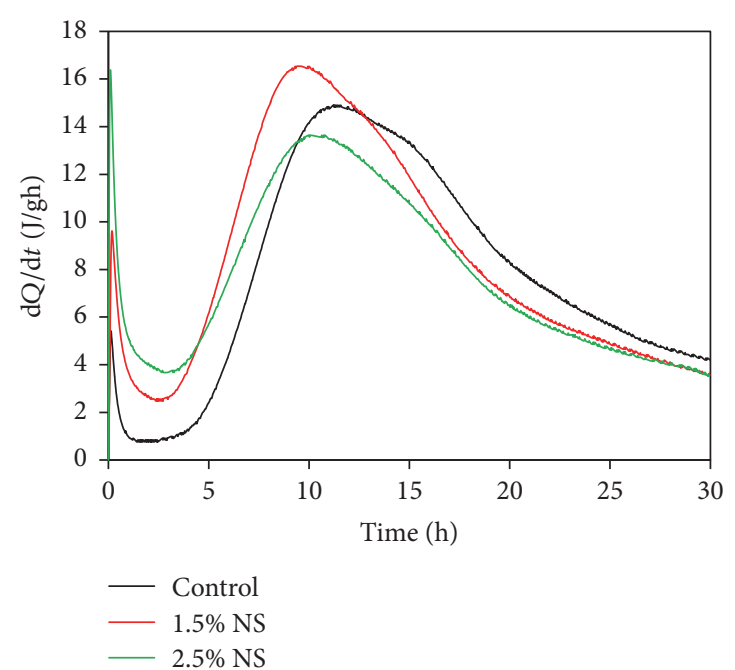

(a)

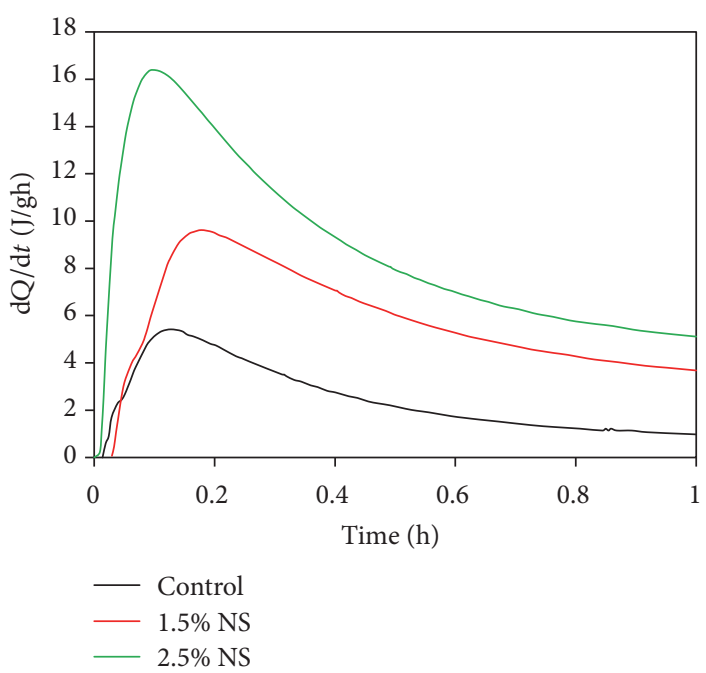

(b)

FIGURE 4: Examples of heat flow curves of the plain pastes and pastes containing $1.5 \%$ and $2.5 \%$ NS in (a) 30 hours and (b) first hour of the hydration.

Microstructural Characterization. Microstructural characterization was performed on the fragments collected from the broken samples of compressive strength test at 28 days of curing. SEM was conducted by Quanta TM 250 FEG on fragments with $2.5 \%$ NS. MIP was performed by Micromeritics 9500 instrument on fragments with NS dosages of $0 \%$ and $2.5 \%$.

\section{Results and Discussion}

3.1. Isothermal Calorimetry of Cement Paste. Variations of heat flow $\mathrm{dQ} / \mathrm{d} t$ per unit weight of cement $(\mathrm{J} / \mathrm{g} \cdot \mathrm{h})$ during initial 30 hours of hydration, as an example, are shown in Figure 4(a) from the time when the dry cement came into contact with mixing liquid (water + NS). The curves exhibited typical peaks of the cement hydration. The first peak of heat flow during first hour of the hydration, as an example for one sample from each mix, is magnified in Figure 4(b).

From Figure 4(b), by increasing NS content from $0 \%$ to $2.5 \%$, amplitude of the first peak increased progressively. From Figure 4(a), the induction period was shortened and the second peak was shifted towards left compared to control. The heat flow in the initial reaction, induction, and acceleratory period for the two mixes containing NS was higher than control. In contrast, the heat flow of the postacceleratory period of cement pastes containing NS was lower than control.

The cumulative heat up to 72 hours is discretized in Figure 5 for each substage. Each column in the figure shows average of two values of the heat, released in each substage of the cement hydration. From Figure 5(a), the amount of heat, released in initial reaction period $(0-1 \mathrm{~h})$, was elevated more than twice with respect to control after adding both NS dosages. This could be interpreted as indicating NS favors superficial dissolution of cement grains. Moreover, the cumulative heat in induction period and acceleratory period was increased compared to control after adding both NS dosages. This could be interpreted as indicating NS can act as extra seed for precipitation of hydration products. On the contrary, from Figure 5(a), the cumulative heat in the postacceleratory period (11-72 h) was progressively decreased after adding $1.5 \%$ and $2.5 \%$ NS with respect to control. This could be interpreted as indicating presence of more compacted hydration products around the cement grain, formed in presence of NS, which hinder diffusion of ions from interior of the grain to its exterior at this substage of hydration.

The total cumulative heat, released after 72 hours of hydration, is depicted in Figure 5(b). Fractions of the heat, released in initial reaction, induction, and acceleratory period (chemical controlled hydration), and that of the postacceleratory period (diffusional controlled hydration) are also shown in the figure. From Figure 5(b), the heat, released by chemical controlled hydration, increased from control value of $75 \mathrm{~J} / \mathrm{g}$ to 94 and $86 \mathrm{~J} / \mathrm{g}$ after adding $1.5 \%$ and $2.5 \%$ NS, respectively, while the heat, released by diffusional controlled hydration, decreased from control value of $237 \mathrm{~J} / \mathrm{g}$ to 223 and $207 \mathrm{~J} / \mathrm{g}$ after adding $1.5 \%$ and $2.5 \%$ NS, respectively. When hydration is chemically controlled, adding NS led to acceleration of the cement hydration compared to the control. In contrast, when hydration is diffusional controlled, adding NS led to deceleration of the hydration. The deceleration of hydration was more severe for $2.5 \%$ NS compared to $1.5 \%$ NS. This can be attributed to the fact that the level of compaction of the hydration products, due to NS presence, around the cement grains may increase with increasing NS dosage.

Total cumulative heat (after 72 hours) is result of cumulative heat of the cement hydration, which is controlled by chemical process and by diffusional process. The total cumulative heat slightly increased from the control value of $312 \mathrm{~J} / \mathrm{g}$ to $317 \mathrm{~J} / \mathrm{g}$ after adding $1.5 \% \mathrm{NS}$, while it decreased to $294 \mathrm{~J} / \mathrm{g}$ after adding $2.5 \%$ NS. The increase of cumulative heat of the 


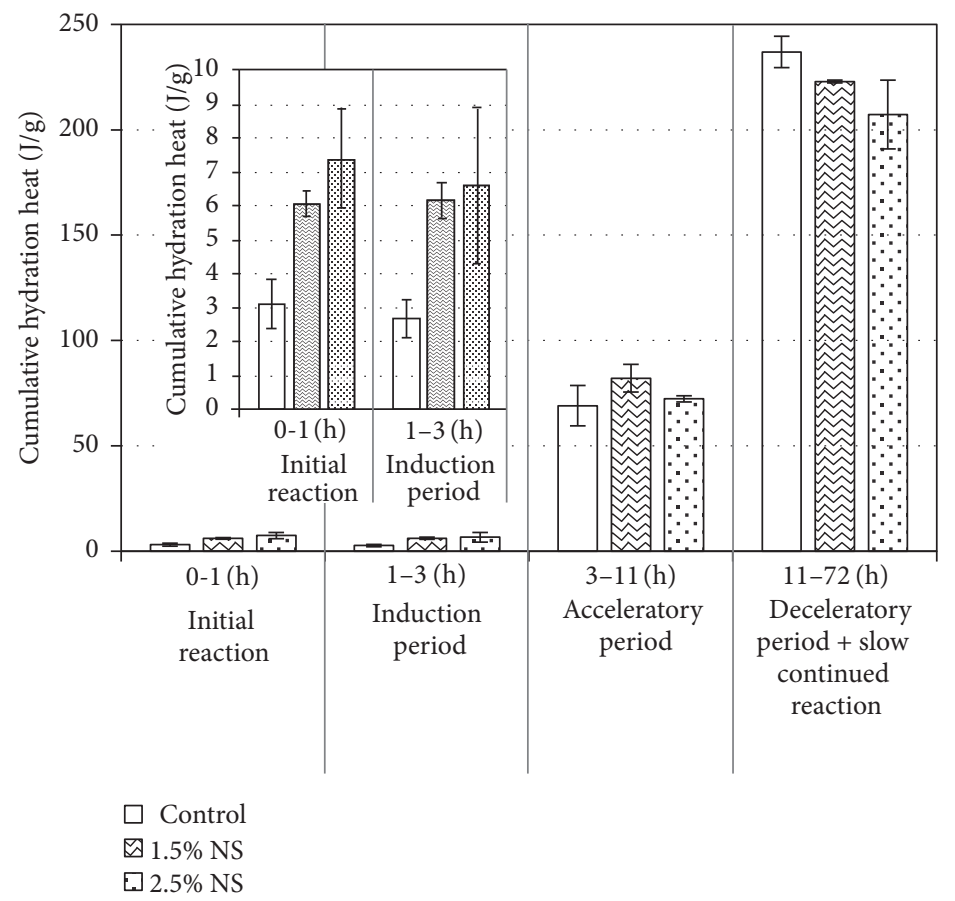

(a)

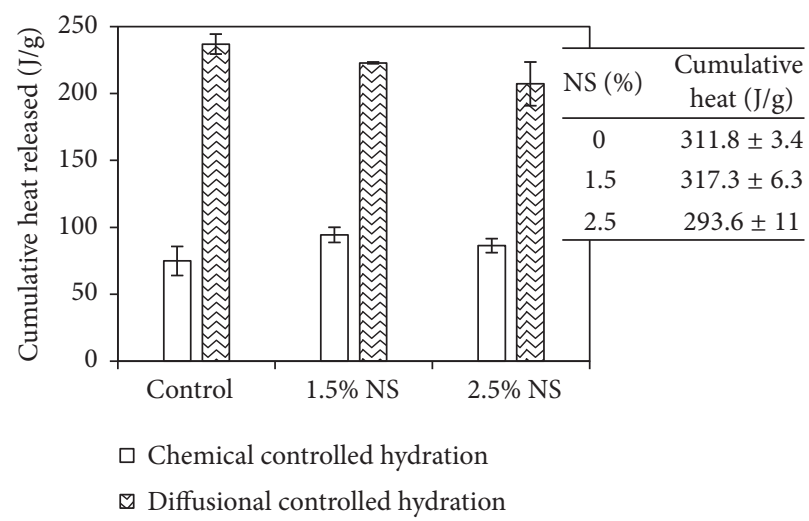

(b)

Figure 5: (a) Cumulative released heat in different substages: 0-1 (h), 1-3 (h), 3-11 (h), and 11-72 (h). (b) Cumulative released heat after 72 hours of hydration, discretized according to the phenomenon (diffusional and chemical) by which hydration is governed. Data of the table represents cumulative heat after 72 hours of hydration.

paste with $1.5 \%$ NS originated from the increase of fraction of chemically controlled hydration and not from that of diffusional controlled hydration. On the other hand, the reduction of the total cumulative heat after adding $2.5 \% \mathrm{NS}$ with respect to control originated from intense reduction of the cumulative heat by diffusional process. These results showed that considering total cumulative heat (e.g., during 72 hours), as a whole, might not correctly represent influence of NS on the cement hydration. NS might have diverse, even contradictory, influence on each of the substages of the hydration.

3.2. Thermal Analysis. Figure 6 shows TGA and DTA curves and weight losses related to $\mathrm{CH}$ and $\mathrm{CC}$ decompositions for the pastes at 28 days of curing. From Figure 6, $\mathrm{CH}$ content and $\beta_{28}$, degree of hydration, were calculated and are presented in Figure 7. From Figure 7(a), CH content was reduced, with a linear trend with respect to NS dosage, from control value of $19 \%$ to $17.2 \%$ and $16 \%$ after adding $1.5 \%$ and $2.5 \%$ NS, respectively. The reduction could be due to pozzolanic activity of NS, which consumed $\mathrm{CH}$.

The following reaction, assuming the entire pozzolanic agent (i.e., NS) was reacted, was proposed for pozzolanic reaction of siliceous pozzolanic additive by Dunstan [21]:

$$
3 \mathrm{Ca}(\mathrm{OH})_{2}+2 \mathrm{SiO}_{2} \longrightarrow 3 \mathrm{CaO} \cdot 2 \mathrm{SiO}_{2} \cdot 3 \mathrm{H}_{2} \mathrm{O}
$$

The above formula suggests the mass ratio of $\mathrm{CH} / \mathrm{SiO}_{2}$ equals 1.85. In this study, mass ratios of $\mathrm{CH} / \mathrm{SiO}_{2}$ (consumed 


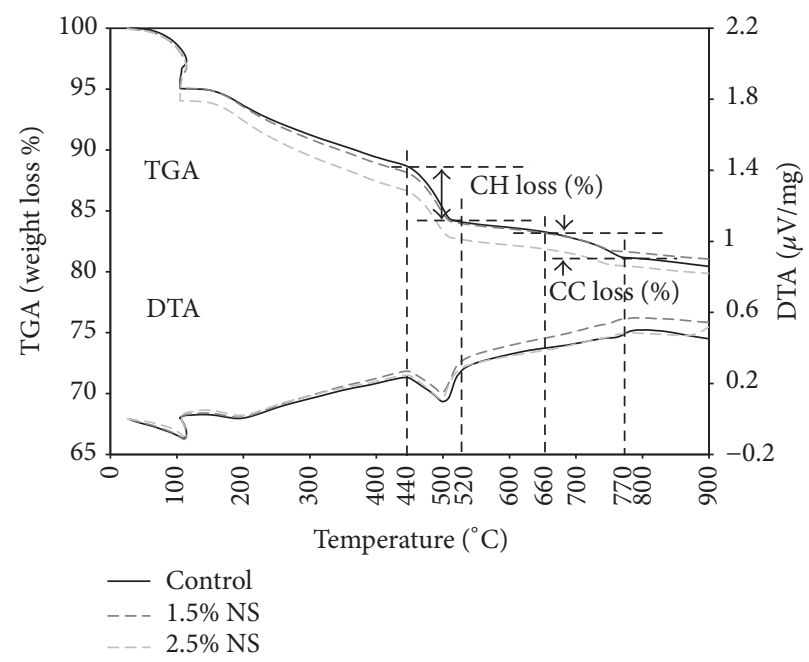

FIGURE 6: TGA and DTA curves for the pastes with and without NS. Weight losses associated with decomposition of CH and CC are shown.

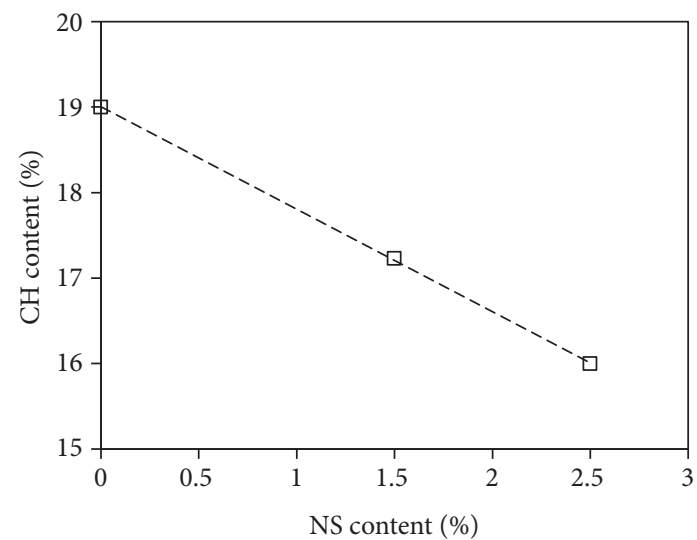

(a)

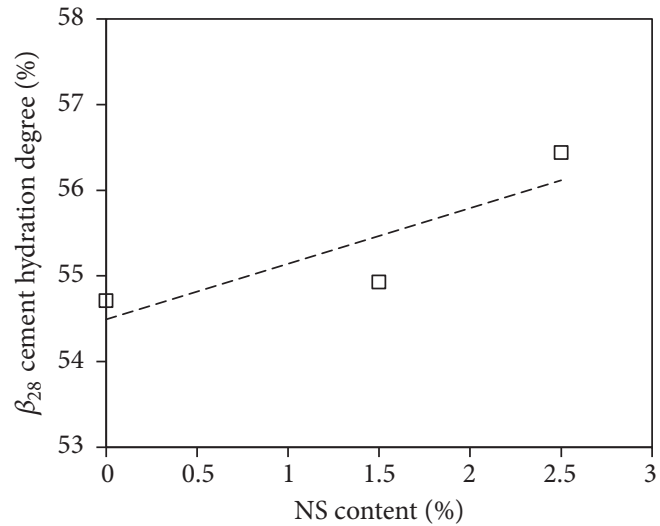

(b)

FIGURE 7: (a) $\mathrm{CH}$ content (\%) and (b) degree of hydration at 28 days of curing as a function of NS content (\%).

$\mathrm{CH}$ and NS content) for the pastes containing $1.5 \%$ and $2.5 \%$ were 1.89 and 1.74 , respectively, which are very close to the value suggested by the formula. As a consequence, occurrence of pozzolanic reaction between $\mathrm{NS}$ and $\mathrm{CH}$ is presumable.

From Figure 7(b), degree of hydration at 28 days of curing slightly increased, relatively with a gentle ascending linear relation with respect to NS content, from the control value of $54.7 \%$ to $56.4 \%$ after adding $2.5 \%$ NS. The method used in this study to evaluate hydration degree is based on the loss-onignition measurement of nonevaporable water content coming from decomposition of hydration products (mainly $\mathrm{CH}$ and $\mathrm{C}-\mathrm{S}-\mathrm{H}$ ). The $\mathrm{C}-\mathrm{S}-\mathrm{H}$, which underwent decomposition, could be either primary C-S-H (by cement hydration) or secondary C-S-H (by pozzolanic activity of NS).

According to Figure 7(b), the increase of hydration degree after adding NS indicates decomposition of higher amount of C-S-H; it is difficult, however, to clarify the type of C-S-H (primary or secondary) that has undergone decomposition. There are two interpretations: if the amount of secondary C$\mathrm{S}-\mathrm{H}$ is negligible, which means that decomposed C-S-H is mainly of primary C-S-H, acceleration of hydration due to NS incorporation could be presumed. Alternatively, if amount of secondary C-S-H cannot be neglected, pozzolanic activity of NS could be responsible for the increase of C-S-H amount.

Regarding addition of relatively small NS dosage to the pastes, see Table 1 , the absolute amount of secondary C-S$\mathrm{H}$ might be small as well, and it is more presumable that the amount of secondary C-S-H is negligible as compared to that of primary $\mathrm{C}-\mathrm{S}-\mathrm{H}$; it is, therefore, reasonable to conclude that NS led to slight acceleration of the hydration at hardened state. Considering the results of Section 3.1, a discrepancy might arise when the amount of secondary C$\mathrm{S}-\mathrm{H}$ is assumed to be negligible. It was found in Section 3.1 that in postacceleratory period NS addition into cement (in both dosages) resulted in deceleration of the hydration rate. The hydration of cement in postacceleratory period would be governed by diffusional process until whole still unreacted cement undergoes hydration reaction. The discrepancy could be explained as follows. It should be noted that Figure 7(b) shows hydration degree at 28 days of curing and not at early 


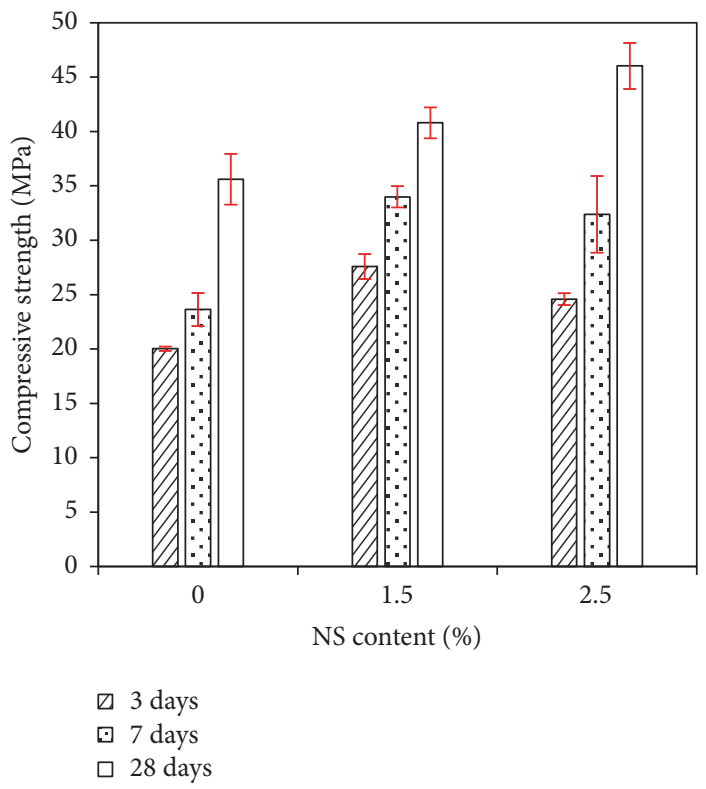

FIGURE 8: Compressive strength of the plain paste and pastes containing 1.5\% and 2.5\% NS after 3 days, 7 days, and 28 days of curing.

ages of hydration. NS addition may delay the hydration at postacceleratory period and, upon the whole, NS did not hinder the hydration at hardened state.

3.3. Compressive Strength. Figure 8 shows compressive strength of the cement pastes with two NS dosages and plain cement paste after 3,7 , and 28 days of curing. Increasing NS content led to progressive increase of compressive strength after 28 days of curing compared to that of control. The 28 days' strength gains of the paste containing $1.5 \%$ and $2.5 \%$ NS were $14.6 \%$ and $30 \%$, respectively, as compared to control. The data related to 3 and 7 days of curing represents beneficial impacts of NS on early age strength of the cement paste.

\subsection{Microstructural Characterization}

Morphology Observation. Figure 9(a) shows micrographs of a fragment containing 2.5\% NS in Environmental Scanning Electron Microscope (ESEM) mode. It shows an interface of a NS agglomerate and cement matrix around. The interface zone was easily detached from the paste, possibly, due to difference of shrinkage during sample drying. The interface zone seems to be weak and thus might be more porous than cement matrix around. Figure 9(b) shows a micrograph of a fragment containing 2.5\% NS in Backscattered Electron (BSE) mode. The figure depicts zones having different morphologies with respect to cement matrix around, which could be agglomerates of NS particles, indicating partial agglomeration of NS particles after coming into contact with cement. The figure shows $\mathrm{Ca} / \mathrm{Si}$ weight ratios of various regions, measured by Energy Dispersive Spectroscopy (EDS). The agglomerates contained higher content of Si with respect to the bulk of cement matrix but they still contained $\mathrm{Ca}$ element. This could be interpreted as indicating diffusion of Ca ions inward NS agglomerates and the agglomerates underwent pozzolanic reaction. The agglomerates might have been formed at early stages, when the mix had been still fresh and workable. The more fluid the fresh cement paste, the coarser the agglomerates. The hydration at early stages might be influenced by level of NS agglomeration. Severe NS agglomeration could reduce capability of NS to accelerate the hydration at early ages; however NS agglomerate could still undergo pozzolanic reaction.

Porosity Analysis. The relationship between pore volume and porosity size is shown for the plain paste and paste containing $2.5 \%$ NS in Figure 10 in which $V$ and $D$ are pore volume and size. The higher the value of $\mathrm{d} V / \mathrm{d} \log D$, the higher the pore volume fraction related to certain pore sizes with respect to total porosity volume. After adding $2.5 \%$ $\mathrm{NS}$, the volume of pores in range of $30-120 \mathrm{~nm}$ increased compared to control, while the volume of the pore in range of $350-1610 \mathrm{~nm}$ decreased. The increase of porosity in the range of $30-120 \mathrm{~nm}$ could be attributed to presence of the porous interface zone between NS agglomerates and cement matrix around, which has been mentioned above. Nevertheless, after adding $2.5 \%$ NS, no considerable change was observed in the total porosity. Volume of porosity could be reduced by products of pozzolanic reaction, for example, secondary C$\mathrm{S}-\mathrm{H}$. In agreement with the assumption made in Section 3.2, that is, the amount of secondary C-S-H was assumed to be negligible, produced secondary $\mathrm{C}-\mathrm{S}-\mathrm{H}$ was not able to influence the porosity.

Porosity of the cement paste is one of the factors influencing its strength. Since the porosity did not considerably change due to NS addition, the compressive strength enhancement could be related to formation of high stiffness C-S-H after adding NS. Some researchers $[8,22]$ found that incorporation of NS into cementitious composites promotes 


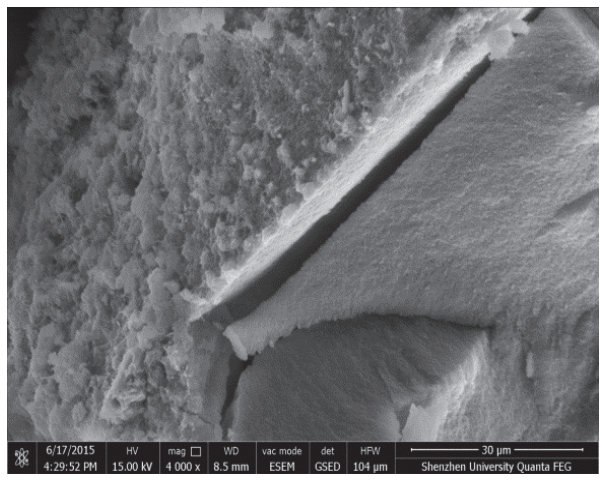

(a)

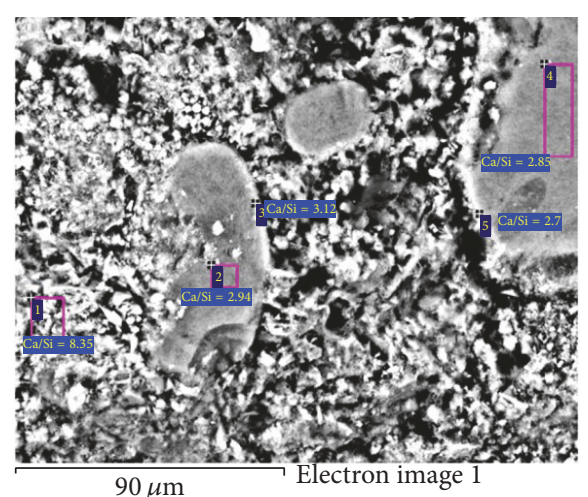

(b)

FIGURE 9: (a) ESEM image of cement paste containing 2.5\% NS, showing an interface of a NS agglomerate and cement matrix around. (b) BSE image of the paste with $2.5 \%$ NS content. Ca/Si weight ratios of different regions, measured by EDS analysis, are shown.

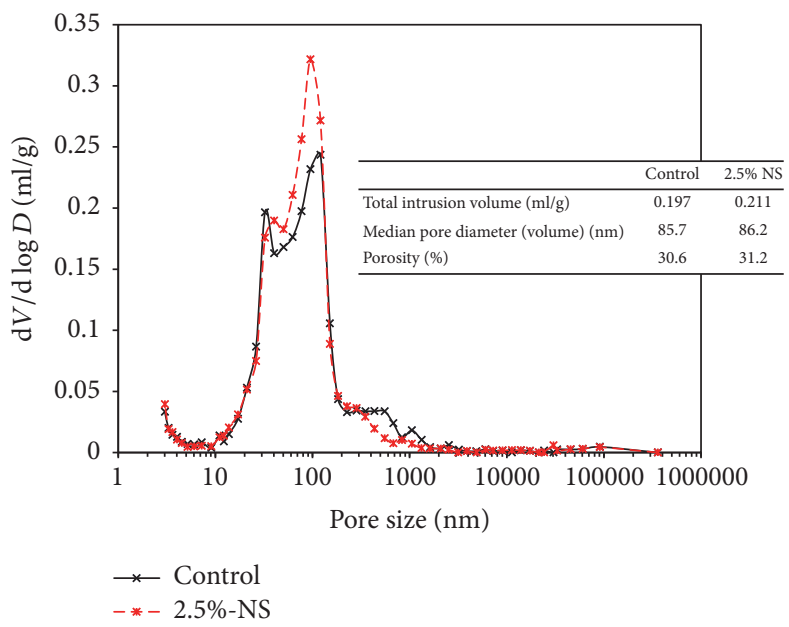

FIGURE 10: Relation between pore volume and pore size for plain paste and paste containing $2.5 \%$ NS.

volume fraction of high stiffness $\mathrm{C}-\mathrm{S}-\mathrm{H}$ in the hydration products.

\section{Conclusions}

Effect of nanosilica on the rate of cement hydration, disregarding various substages of hydration, has been broadly investigated in the literature. However, the hydration of cement paste is characterized by different substages and nanosilica effect on the hydration could be a result of diverse, even contradictory, behavior of nanosilica in different substages of the hydration. In this study, effects of NS on substages of cement hydration were investigated.

The isothermal calorimetry revealed that when the hydration was chemically controlled, that is, during initial reaction, dormant period, and acceleratory period, the hydration rate was accelerated by adding nanosilica.

When the hydration was governed by diffusion process, that is, during postacceleratory period, the hydration rate was decelerated by adding nanosilica, presumably, as a consequence of formation of more compacted hydration product around the cement grains due to presence of nanosilica. As a result, diffusion of ions at this stage through the hydration products and outward of the cement grain might be slower in presence of nanosilica than that in the plain paste.

The Thermal Gravimetric Analysis revealed that, after adding nanosilica, the hydration degree slightly increased compared to the plain paste at the hardened state.

The compressive strength was progressively elevated after adding both nanosilica dosages into the cement paste.

The micrograph of the cement paste containing $2.5 \%$ nanosilica showed agglomeration of nanosilica after addition into the paste. The agglomerates, however, were hydrated, showing diffusion of ions inward bulk of the agglomerates.

The porosity of the paste containing $2.5 \%$ nanosilica with respect to the plain paste did not considerably change.

\section{Conflicts of Interest}

The authors declare that there are no conflicts of interest regarding the publication of this article. 


\section{Acknowledgments}

The work received partial funding by the European IRSES project (DOSECOPS) "Development of Sustainable Electrochemical Corrosion Protection Systems for Reinforced Concrete Structures" (Project no. FP7-PEOPLE-2011-IRSES294555) and by the Shenzhen Strategic Emerging Industry Development Special Fund (no. JCYJ20150625102603853), the National Natural Science Foundation of China (Grant no. 51378303), and the Guangdong Province Science and Technology Plan Projects (Project no. 2015A010105029).

\section{References}

[1] B. W. Jo, C. H. Kim, J. H. Lim KSCE, and J. Civ, Civ. Eng., 2007.

[2] L. P. Singh, S. K. Bhattacharyya, and S. Ahalawat, "Preparation of size controlled silica nano particles and its functional role in cementitious system," Journal of Advanced Concrete Technology, vol. 10, no. 11, pp. 345-352, 2012.

[3] S. Haruehansapong, T. Pulngern, and S. Chucheepsakul, "Effect of the particle size of nanosilica on the compressive strength and the optimum replacement content of cement mortar containing nano-SiO ${ }_{2}$, Construction and Building Materials, vol. 50, pp. 471-477, 2014.

[4] M. Jalal, E. Mansouri, M. Sharifipour, and A. R. Pouladkhan, "Mechanical, rheological, durability and microstructural properties of high performance self-compacting concrete containing $\mathrm{SiO} 2$ micro and nanoparticles," Materials and Design, vol. 34, pp. 389-400, 2012.

[5] F. U. A. Shaikh and S. W. M. Supit, "Chloride induced corrosion durability of high volume fly ash concretes containing nano particles," Construction and Building Materials, vol. 99, pp. 208225, 2015.

[6] F. T. Isfahani, E. Redaelli, F. Lollini, W. Li, and L. Bertolini, "Effects of nanosilica on compressive strength and durability properties of concrete with different water to binder ratios," Advances in Materials Science and Engineering, vol. 2016, Article ID 8453567, 16 pages, 2016.

[7] J. Björnström, A. Martinelli, A. Matic, L. Börjesson, and I. Panas, "Accelerating effects of colloidal nano-silica for beneficial calcium-silicate-hydrate formation in cement," Chemical Physics Letters, vol. 392, no. 1-3, pp. 242-248, 2004.

[8] J. J. Gaitero, I. Campillo, P. Mondal, and S. P. Shah, "Small changes can make a great difference," Transportation Research Record, no. 2141, pp. 1-5, 2010.

[9] D. Kong, Y. Su, X. Du, Y. Yang, S. Wei, and S. P. Shah, "Influence of nano-silica agglomeration on fresh properties of cement pastes," Construction and Building Materials, vol. 43, pp. 557562, 2013.

[10] P. Hou, S. Kawashima, D. Kong, D. J. Corr, J. Qian, and S. P. Shah, "Modification effects of colloidal nanoSiO 2 on cement hydration and its gel property," Composites Part B: Engineering, vol. 45, no. 1, pp. 440-448, 2013.

[11] G. Land and D. Stephan, "The influence of nano-silica on the hydration of ordinary Portland cement," Journal of Materials Science, vol. 47, no. 2, pp. 1011-1017, 2012.

[12] D. Kong, X. Du, S. Wei, H. Zhang, Y. Yang, and S. P. Shah, "Influence of nano-silica agglomeration on microstructure and properties of the hardened cement-based materials," Construction and Building Materials, vol. 37, pp. 707-715, 2012.
[13] F. Massazza, Lea's Chemistry of Cement and Concrete, John Wiley and Sons Inc., 4th edition, 1997.

[14] A. M. Neville, Properties of Concrete, John Wiley \& Sons, 1973.

[15] O. Mendoza, G. Sierra, and J. I. Tobon, "Effect of the reagglomeration process of multi-walled carbon nanotubes dispersions on the early activity of nanosilica in cement composites," Construction and Building Materials, vol. 54, pp. 550-557, 2014.

[16] F. Torabian Isfahani, W. Li, and E. Redaelli, "Dispersion of multi-walled carbon nanotubes and its effects on the properties of cement composites," Cement and Concrete Composites, vol. 74, pp. 154-163, 2016.

[17] H. F. W. Taylor, Cement Chemistry, 2nd edition, 1992.

[18] J. Hu, Z. Ge, and K. Wang, "Influence of cement fineness and water-to-cement ratio on mortar early-age heat of hydration and set times," Construction and Building Materials, vol. 50, pp. 657-663, 2014.

[19] I. Pane and W. Hansen, "Investigation of blended cement hydration by isothermal calorimetry and thermal analysis," Cement and Concrete Research, vol. 35, no. 6, pp. 1155-1164, 2005.

[20] R. Yu, P. Spiesz, and H. J. H. Brouwers, "Effect of nano-silica on the hydration and microstructure development of Ultra-High Performance Concrete (UHPC) with a low binder amount," Construction and Building Materials, vol. 65, pp. 140-150, 2014.

[21] E. R. Dunstan, "World of Coal Ash (WOCA) conference," 2011.

[22] P. Mondal, S. P. Shah, L. D. Marks, and J. J. Gaitero, "Comparative study of the effects of microsilica and nanosilica in concrete," Transportation Research Record Journal of the Transportation Research Board, vol. 2141, pp. 6-9, 2010. 

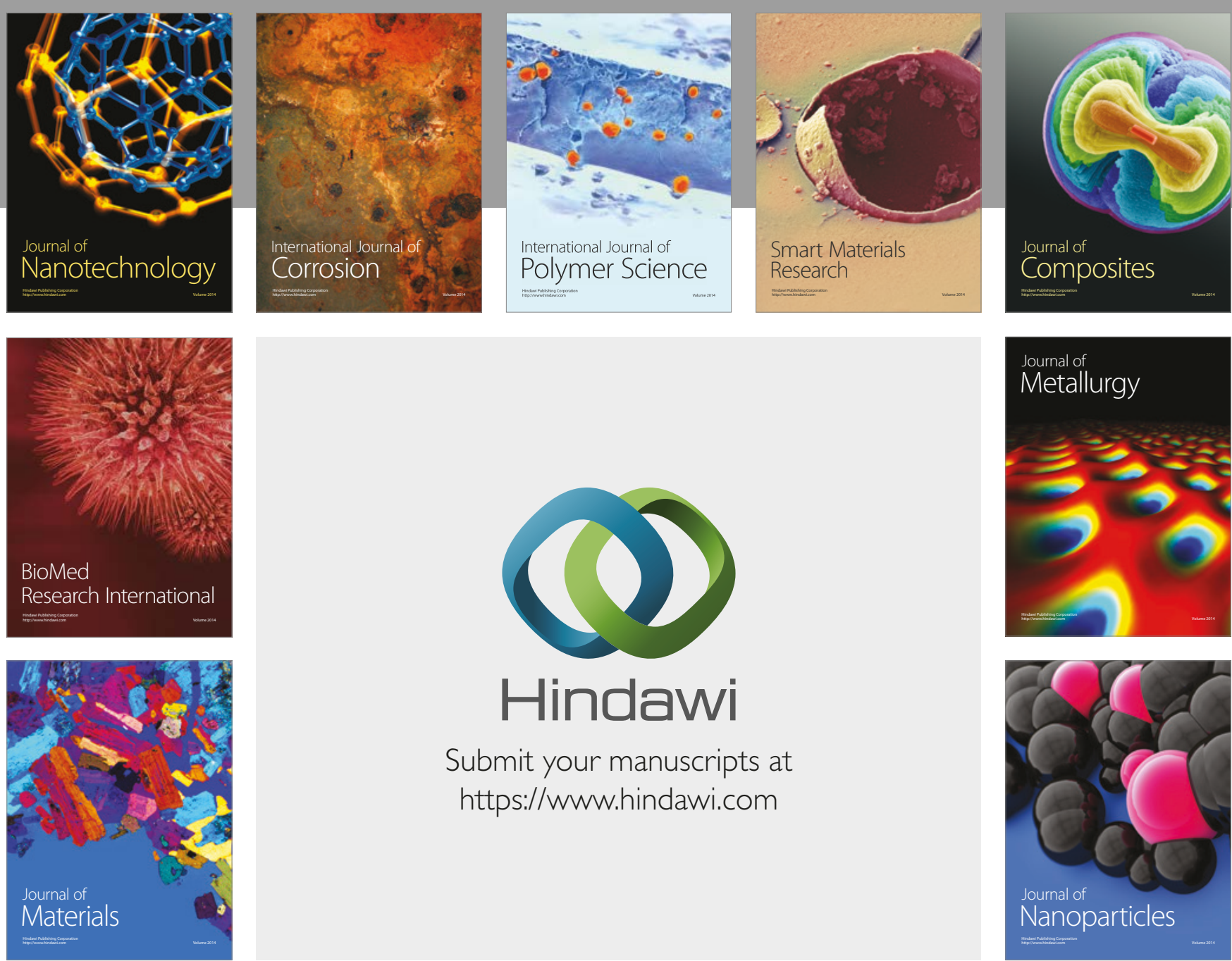

\section{Hindawi}

Submit your manuscripts at

https://www.hindawi.com
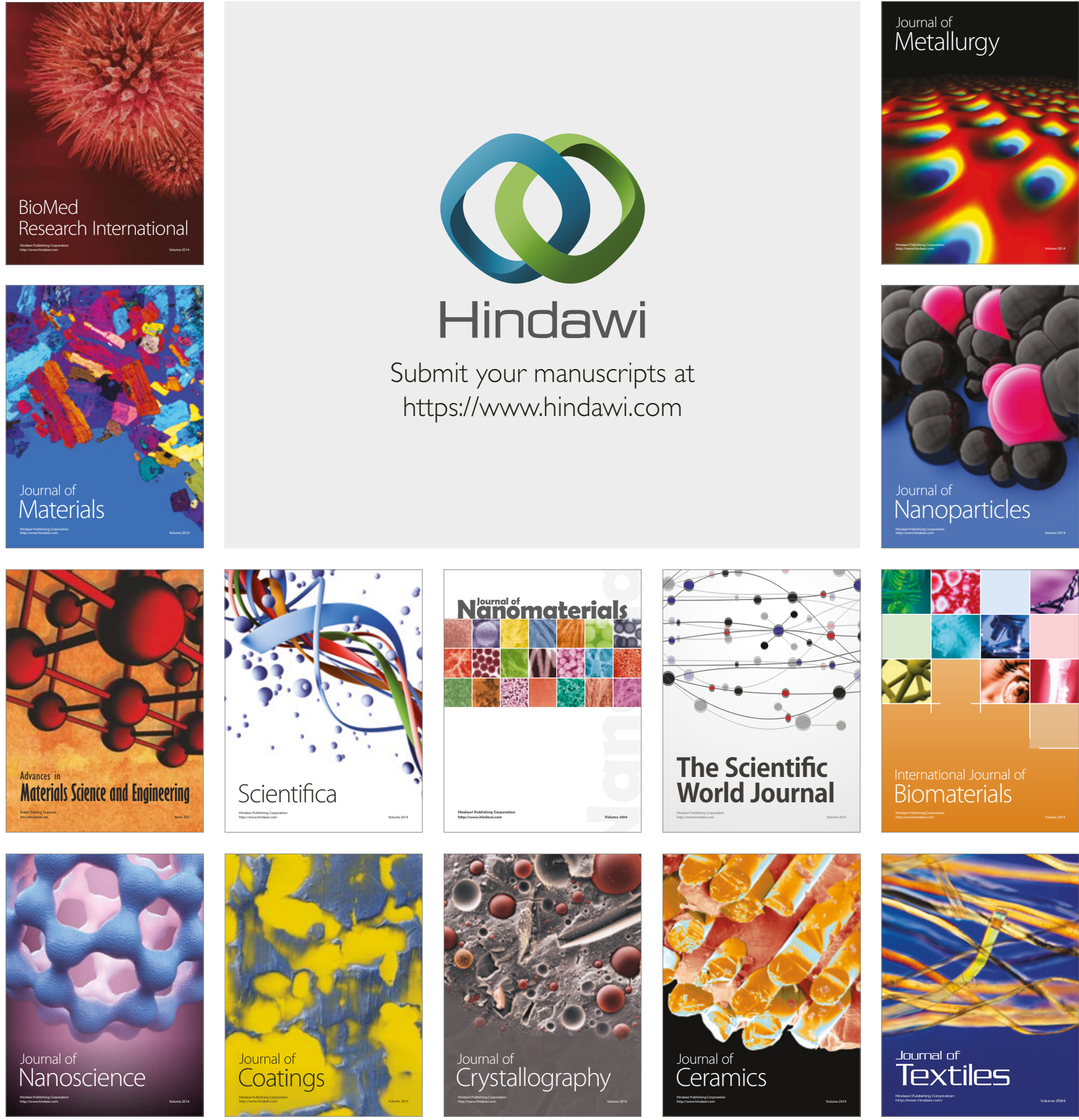

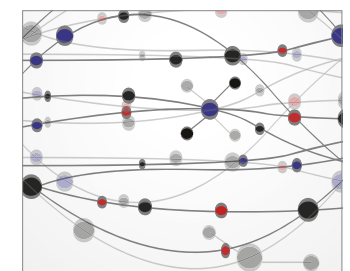

The Scientific World Journal
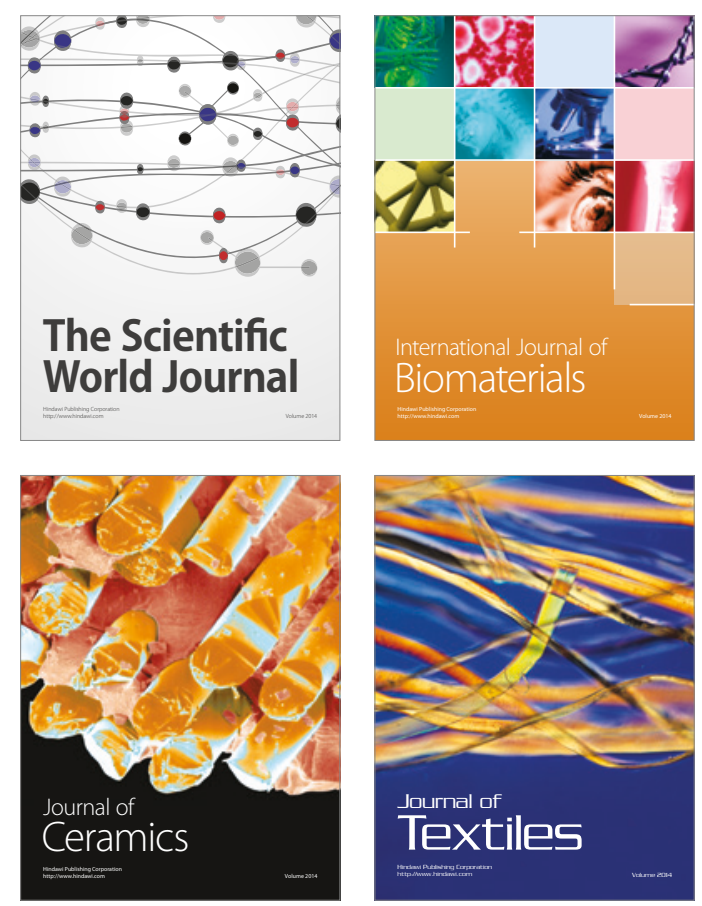